\title{
Transfronterización de enfermedades infecciosas en la camaronicultura. Una revisión
}

\author{
Alexander Varela-Mejías ${ }^{1}$ \& Nelson Peña-Navarro ${ }^{2}$ \\ 1. Laboratorio de Patologías y Parasitología de Crustáceos. Nicoya, Costa Rica. Autor para correspondencia: \\ alexander.varela@gmail.com \\ 2. Universidad Técnica Nacional de Costa Rica. Apartado postal: 148-5400 Puntarenas.
}

Recibido: 10 de diciembre, 2016

Aceptado: 16 de enero, 2017

\begin{abstract}
RESUMEN
El cultivo de camarones marinos se ha visto afectado por gran cantidad de agentes infecciosos; los cuales se han propagado entre regiones, países e incluso continentes. Dando lugar a un fenómeno llamado transfronterización, el cual ha sido acelerado por las actividades humanas propias del comercio y la globalización. La disponibilidad local de larvas o reproductores de camarones en algunas países, es insuficiente e incluso inexistente, provocando el movimiento de especímenes entre países, y como consecuencia de ello, varias enfermedades han sido introducidas, entre ellas el Virus del síndrome de las manchas blancas, el Virus del síndrome de Taura, el Virus de la Mionecrosis infecciosa, el Parvovirus hepatopancreático, el Virus de la cabeza amarilla y recientemente la Necrosis aguda del hepatopáncreas. La falta de control efectivo de los movimientos de organismos acuáticos entre países, ha facilitado la proliferación de brotes de enfermedades que una vez introducido el patógeno y establecido en el ambiente natural y de cultivo, su erradicación es casi imposible.
\end{abstract}

Palabras clave: transfronterización, patología, camarones, globalización.

\section{ABSTRACT \\ TRANSBOUNDARY OF INFECTIOUS DISEASES IN SHRIMP FARMING. A REVIEW}

The shrimp farming has seen affected by great amount of infectious agents, which is have propagated between regions, countries and even continents. Giving rise to a phenomenon called transboundary of pathologies, which has been accelerated by the human activities own of the trade and the globalization. The local availability of larvae or spawners of shrimp in some countries, is insufficient and even non-existent, causing the movement of specimens between countries, and as a result, several diseases have been introduced, including the White spot syndrome Virus, Taura syndrome Virus, the Infectious myonecrosis virus, Hepatopancreatic Parvovirus, Yellow head virus and recently Acute hepatopancreatic necrosis disease. The absence of effective control over movements of aquatic organisms between countries, has facilitated the proliferation of outbreaks of diseases that once introduced the pathogen and established in the wild and cultivated, its eradication is almost impossible.

Key words: Transboundary, pathology, shrimp, globalization.

\section{Introducción}

La acuicultura en sus diferentes modalidades o sistemas, consiste en las técnicas de producción de especies acuícolas, realizada en espacios y ambientes acuáticos controlados, generalmente utilizando alimentación complementaria artificial para el desarrollo de los animales (Varela, 2011).

De acuerdo con datos reportados por la FAO, la producción acuícola mundial alcanzó 90,4 millones de toneladas en el año 2012. De ellos, 66,6 millones de toneladas correspondían a especies comestibles, incluida la producción de camarón de cultivo, el cual representó el $9,7 \%$, para 6,4 millones de toneladas, y el $22,4 \%$ en valor, los cuales a su vez correspondieron al $15 \%$ del valor total de los productos pesqueros comercializados a nivel internacional durante ese año (Morales y Cuéllar-Ánjel; 2014).

Durante los últimos años, la producción de la acuicultura ha presentado un aumento constante, a diferencia de las capturas naturales, las cuales presentan un estancamiento generado 
por la sobreexplotación de los cuerpos de agua. Por ahora, este incremento ha compensado los efectos del estancamiento en capturas, así como el crecimiento de la población humana y su demanda. En este sentido, el cultivo de camarón es el rubro de la acuicultura con más rápido crecimiento en Asia y Latinoamérica y recientemente en África (Cuéllar-Ánjel et al. 2014).

Datos recientes de la FAO (2016), indican que la oferta mundial per capita de peces y mariscos alcanzó un máximo histórico de $20 \mathrm{~kg}$ en 2014, logrado gracias al intenso crecimiento de la acuicultura, que en la actualidad proporciona la mitad de todo el pescado destinado al consumo humano; además, la producción acuícola mundial representó el 44,1 \% de la producción total de la pesca de captura y la acuicultura en el 2014, una cifra que supera al $42,1 \%$ alcanzado en 2012 y al 31,1 \% registrado en 2004. Además, todos los continentes han mostrado una tendencia general de aumento en sus producciones acuícolas.

El aporte socioeconómico de esta actividad es asimismo, de gran importancia. Se estima que millones de personas encuentran su fuente de ingresos en el sector de la pesca y la acuicultura. Las cifras más recientes indican que 56,6 millones de personas trabajaban en 2014 en el sector primario de la pesca de captura y acuicultura. De este total, el $36 \%$ trabajaba a tiempo completo, el $23 \%$ a tiempo parcial y los demás son pescadores ocasionales o de situación sin especificar (FAO, 2016).

Entre las especies acuícolas, los crustáceos han logrado grandes niveles de producción, incluyendo a los llamados decápodos, denominados así por poseer diez extremidades, tales como las langostas, camarones y cangrejos. Estos animales han sido ampliamente investigados, no solo por estar presentes en múltiples ambientes acuáticos, sino además, por su rol histórico e importancia en la nutrición humana. El grupo comprende al menos 14.750 especies, tanto marinas como dulceacuícolas (Vogt, 2012).

Entre éstas, la especie más cultivada a nivel mundial es el camarón blanco del Pacífico, Penaeus vannamei, perteneciente a la familia Penaeidae, y originaria del Pacífico Americano, sus adultos son de hábitos marinos, en tanto que las formas larvales son estuarinas. Sus especímenes han sido encontrados desde los 2 hasta los 160 metros de profundidad, y viven asociados a zonas litorales fangosas (Hendrickx, 1995; Lee y Wickins, 1992; Morales-Covarrubias, 2010).

Paralelamente al crecimiento de las producciones, tal como ocurre en toda actividad humana, en la acuicultura se generan impactos en el ambiente, estos impactos pueden ser estos positivos o negativos. Según López et al. (2012), el grado del impacto de la actividad acuícola dependerá en gran medida de la especie cultivada, del método de cultivo utilizado, de la densidad de los animales por área de cultivo, del tipo de alimentación aplicada y de las condiciones hidrográficas. Asimismo, entre los impactos ambientales positivos se tiene que la acuicultura permite obtener grandes cantidades de productos para consumo, sin extraerlos de poblaciones naturales (FAO, 2016), promoviendo su recuperación.

López, Ojeda y Creainnova (2012), indican que los efectos de dichos impactos pueden darse tanto en la columna de agua como en los fondos y sus efectos pueden ser físicos, químicos y biológicos. En este último rubro se incluye el riesgo por fuga de especímenes ajenos a su ambiente natural. Así como provocar, facilitar o acelerar la introducción de enfermedades exóticas a nuevas regiones (Bondad-Reantaso et al, 2001; Lightner y Pantoja, 2001; López et al. 2012).

Sobre ello, la camaronicultura es constantemente afectada por enfermedades infecciosas. Mismas que son causadas por agentes de diferentes tipos, principalmente virus, bacterias, parásitos y hongos (Bondad-Reantaso et al, 2001; Cuéllar-Ánjel et al. 2014; Lightner, 1996; Lightner y Pantoja, 2001; Morales-Covarrubias, 2010; Peña y Varela, 2016).

La incidencia e impacto de estas enfermedades no es reciente, ya en el siglo pasado se atribuía a los patógenos, la disminución importante en las producciones de camarón en Taiwán y Hawai (Lee y Wickins, 1992).

Concordando con ello, Vogt (2012), indica que las enfermedades de tipo viral han generado serios impactos en la camaronicultura, afectando 
económicamente a sus cultivos y resultando en altas mortalidades. Menciona que cerca de 20 enfermedades que han sido asociadas a mortalidades en masa de los cultivos. Entre ellas el virus del síndrome de las manchas blancas, el virus de la cabeza amarilla, el virus del síndrome de Taura y el virus de la necrosis hipodérmica y hematopoyética infecciosa, este último causando mortalidades mayores al $90 \%$ de los cultivos de camarones en Hawai en 1981.

Sobre este particular, Lightner y Pantoja, (2001), concuerdan con que las enfermedades de camarón han impactado fuertemente a las producciones acuícolas a nivel mundial. Se ha publicado que algunas de estas enfermedades han sido introducidas de país en país por medio del transporte de camarones vivos o congelados, ocasionando pérdidas de millones de dólares (Bondad-Reantaso et al, 2001; Lightner, 1996; Lightner y Pantoja; OIE, 2016; Peña y Varela, 2016; Varela y Peña, 2013).

Ahora bien, antes de continuar, es importante aclarar que la existencia de patologías en organismos acuáticos, no corresponde a una consecuencia exclusiva de las actividades humanas, siendo un fenómeno totalmente natural. La primer infección viral documentada para un invertebrado acuático, fue reportada por Vago en 1966, en el cangrejo braquiuro Macropipus depurator (Kinne 1990). De hecho, se considera que los virus probablemente infectan a todas las especies que habitan las aguas marinas, e incluso, que participan como una causa importante de enfermedades y mortalidades en los océanos (Vega-Heredia et al. 2011).

Numerosos trabajos han sido realizados sobre diferentes especies de crustáceos, y confirman este hecho. Indudablemente, las especies silvestres son afectadas por múltiples patologías y parasitologías dentro de su ambiente natural. Existen múltiples estudios que lo conforman, por ejemplo, los realizados sobre la Langostilla Munida subrugosa en Argentina (Martorelli et al. 2003), y diferentes tipos de cangrejos como Chionoecetes opilio en Canadá (Pestal et al. 2003, Wheeler et al. 2007), Cancer pagurus en las costas de Inglaterra (Stentiford et al. 2002), Callinectes sapidus en USA (Noga et al. 2000); Ucides cordatus en Brasil (Vieira et al. 2004); Leptodius exaratus en Hong Kong (Chan et al. 2005); Chlorodiella nigra y C. xishaensis en Australia (Shields 2001), especies de langostas como Jasus edwardsii y J. verreauxi (Diggles 1999); muchos otros ejemplos han sido publicados.

A pesar de ello, los riesgos de introducción de especies exóticas, que sean a la vez portadoras de enfermedades es real y latente (BondadReantaso et al, 2001; Bondad-Reantaso y Arthur 2008, Diéguez-Uribeondo 1998, Lightner y Pantoja, 2001; Walker y Winton, 2010). Dichos riesgos pueden ser incrementados por factores locales. Los brotes de enfermedades se presentan por la interacción de variables ambientales o de manejo, presencia de agentes patógenos y condiciones sub-óptimas tanto nutricionales como inmunológicas de los organismos en cultivo (Balbuena, 2011; Bondad-Reantaso et al, 2001).

La diseminación de patógenos en camaronicultura, ha propiciado que agentes infecciosos ubicados en puntos focales, hayan sido reportados posteriormente en regiones distantes, en ocasiones incluso transcontinentales. Esta "transfronterización" de enfermedades está demostrada, y exige de la aplicación de buenas prácticas de cultivo y medidas de bioseguridad eficaces y rigurosas (Arthur et al 2008, Bondad-Reantaso y Arthur, 2008; Cuéllar-Ánjel et al, 2014; Lightner y Pantoja, 2001; Walker y Winton, 2010).

Esto es especialmente importante al considerar que en Asia y Latinoamérica, es común el comercio de estadíos inmaduros de especies acuícolas entre países o regiones. Las industrias que se ven obstaculizadas debido a producciones locales insuficientes o inexistentes de postlarvas o reproductores, realizan movimientos constantes de organismos en grandes cantidades. Las exigencias del mercado y la globalización que experimentamos otras áreas productivas, no es ajena a la acuicultura (Arthur et al 2008, Bondad-Reantaso \& Arthur, 2008).

Consecuentemente, la intensificación de los sistemas de producción camaronera, así como la realización de movimientos de animales y alimentos a nivel nacional e internacional, 
son algunos de los factores que han condicionado la diseminación de las enfermedades conocidas, así como la aparición de patologías emergentes (Arthur et al 2008, de Blas \& Muniesa 2014).

Debido en gran parte al volumen de animales vivos, objeto de comercio internacional, es realmente complicado evitar la introducción y propagación transfronteriza de especies patógenas exóticas. Éstas, una vez introducidas y establecidas, pueden afectar seriamente tanto a las industrias locales existentes como a las especies acuáticas locales. Los países en desarrollo, debido en parte a la falta de conocimientos, capacidad, políticas y recursos financieros, son especialmente susceptibles a esta amenaza (Bondad-Reantaso y Arthur, 2008).

Los ejemplos de propagación de patógenos acuícolas abundan, algunos presentan un rango geográfico de distribución tan amplio, que actualmente son considerados de afectación mundial. Tal es el caso del Virus de la necrosis hipodérmica y hematopoyética infecciosa, descrito originalmente en Hawai (Bondad-Reantaso et al. 2001, Lightner 1996, Lightner y Pantoja, 2001; OIE, 2016, Rai et al. 2012). El cual es considerado actualmente como más estable de todos los conocidos que afectan a los camarones peneidos. Los tejidos infectados, se mantienen infecciosos, aun después de repetidos ciclos de congelación y descongelación (OIE, 2016).

Ante ello, los códigos o normas desarrollaos de buenas prácticas de producción, que fueron concebidos originalmente como expresiones voluntarias de compromiso de autorregulación para corregir o mejorar los impactos ambientales y las malas prácticas sociales, se han adoptado en algunos casos como interesantes herramientas para el control de los impactos ambientales complejos (Arthur, 2008; Cuéllar-Ánjel et al, 2014; López et al, 2012).

Es oportuno mencionar que ninguno de los patógenos descritos para camarones, posee la capacidad de infectar o afectar a los humanos, por lo que actualmente, se considera que los camarones no poseen riesgo zoonótico. Al igual que otros productos acuícolas, constituyen un producto alimenticio muy nutritivo, con alto contenido proteico y muy versátil. Su único riesgo lo constituye el hecho de ser un producto muy perecedero y puede dañarse con mayor velocidad otros alimentos. Principalmente debido a la proliferación microbiana, a los cambios en su composición química y a la descomposición causada por sus propias enzimas. En consecuencia, es preciso tener especial cuidado en la manipulación de estos productos para evitar su contaminación post cosecha (FAO, 2016; Varela, 2011).

Resumiendo, se trata de un producto de muy alto valor nutritivo, que constituye una fuente de gran cantidad de trabajo e ingresos, difícil de producir, entre otras razones por las enfermedades, y de manejo post cosecha delicado. Con este marco, el objetivo de la presente revisión, es exponer datos sobre algunas de las principales enfermedades infecciosas que afectan la camaronicultura y su relación transfronteriza. Considerando la importancia que la acuicultura ha adquirido a nivel mundial.

\section{Principales enfermedades transfronterizas en el cultivo de camarón}

Virus del síndrome de las manchas blancas.

Sin duda, el agente infeccioso más importante para los crustáceos por su patogenicidad, virulencia, impacto económico y distribución. Ha sido clasificado como Whispovirus (BondadReantaso et al. 2001, Lightner 1996, 2001, Varela y Peña 2013). Tiene la particularidad de afectar a gran cantidad de especies de crustáceos. Ha sido reportado en múltiples especies silvestres con una alta prevalencia en poblaciones silvestres. Para especies cultivadas o de importancia en capturas se ha reportado en Penaeus japonicus, $P$. chinensis, $P$. indicus, $P$. merguiensis, $P$. monodon, $P$, setiferus, $P$. stylirostris, $P$. vannamei, y se ha demostrado la susceptibilidad de $P$. aztecus y $P$. duorarum, Cherax destructor, $C$. quadricarinatus, Procambarus clarkii, Solenosera indica y Homarus gammarus (Lightner 1996; BondadReantaso et al, 2001; Lightner y Pantoja 2001; OIE, 2016; Varela y Peña. 2013). Hasta ahora, no se ha observado que ningún crustáceo 
decápodo de aguas marinas y salobres o dulces sea resistente a infecciones por este patógeno (OIE, 2016).

Sus primeros reportes datan de 1991, con brotes ocasionaron fuertes mortalidades en cultivos de camarones en Taiwán, extendiéndose a Japón y rápidamente, al resto de Asia, provocando drásticas reducciones en la producción. El primer diagnóstico confirmado de este virus en el continente americano se realizó en U.S.A, en el año 1995, en una granja de cultivo de camarones de la especie Penaeus setiferus, ubicada cerca de una planta de procesamiento de camarones cultivados importados desde Asia, por lo que se considera ésta como la ruta probable de introducción (Lightner y Pantoja 2001). Esto se debió que su infectividad, a partir de tejidos congelados, mismos que han sido demostrada experimentalmente (Soto et al. 2001). Posteriormente, en 1999, fue detectado en Ecuador y a finales del mismo año se comprobó su presencia en al menos nueve países de Norte, Centro y Sur América (Bondad-Reantaso et al, 2001; Morales-Covarrubias, 2010; Varela y Peña, 2013). Desde entonces se ha notificado en crustáceos de China, Japón, Corea, el sudeste asiático, el sur de Asia, la India, el Mediterráneo, Oriente Medio y América (OIE, 2016).

\section{Virus del síndrome de Taura}

Inicialmente se presentó gran controversia sobre la causa real de las mortalidades observadas en camaroneras de Guayaquil, Ecuador. Se presentaron incluso teorías sobre toxicidad por agroquímicos, hasta que se descubrió la causa infecciosa, siendo éste un representante de la familia Dicistroviridae (OIE, 2016).

Las especies susceptibles a este virus son principalmente Penaeus vannamei y P. stylirostris. Sin embargo, otras especies pueden resultar infectadas sin desarrollan síntomas como $P$. setiferus, $P$. monodon, $P$. chinensis, $P$. japonicus, $P$. aztecus, $P$. duorarum y $P$. indicus (Lightner, 1996; Bondad-Reantaso et al. 2001; OIE, 2016).

Este virus surgió durante el año 1992 como una enfermedad que afectaba al camarón blanco Penaeus vannamei, en cultivos realizados en la región de la desembocadura del río Taura, región desde la cual se extendió rápidamente por muchas regiones de cultivo de camarones en América, mediante el envío de postlarvas y reproductores infectados. Se trata de un virus capaz de causar altas mortalidades, afectando al $90 \%$ de las poblaciones de los estanques infectados (Lightner, 1996; Morales-Covarrubias, 2010; OIE, 2016).

Siete años posterior a su descubrimiento, este virus fue introducido en Asia, ingresando a través de China en 1999, mediante la importación de camarones juveniles infectados procedentes de América (Tu et al. 1999), posterior a su ingreso, se ha expandido a otras regiones y ha sido detectado en Tailandia, Malasia e Indonesia, y más recientemente en Arabia (Lightner, 1996; Bondad-Reantaso et al. 2001; OIE, 2016; Tang et al, 2012; Pantoja y Lightner 2014a).

\section{Virus de la mionecrosis infecciosa}

Se trata de un totivirus que ha fue reportado por primera vez en la costa Noreste de Brasil durante el año 2002, se caracteriza por ocasionar una severa necrosis del músculo de los animales infectados, causando serios problemas productivos y mortalidades acumuladas del $70 \%$ de los animales cultivados. La especie susceptible a su infección es el $P$. vannamei. Además, experimentalmente se han realizado infecciones en $P$. stylirostris y $P$. monodon, las cuales no causan mortalidades (OIE, 2016; Pantoja y Lightner, 2014ª ; Pereira et al. 2014).

Esta enfermedad viral se dispersó por múltiples regiones camaronícolas de Brasil y posteriormente se diseminó a Indonesia, en el sureste de Asia. Sobre este hecho, se considera que la ruta de entrada posible fue mediante la introducción de camarones infectados desde Brasil (Senapin et al. 2007; OIE, 2016; Pantoja y Lightner 2014a; Pereira et al. 2014).

Informes posteriores reportan su presencia en el oeste de Java, Sumatra, Bangka, el oeste de Borneo, el sur de Sulawesi, Bali, Lombok y Sumbaw. Existen además, informes no oficiales sobre otros países del sureste asiático afectados (OIE, 2016). 


\section{Parvovirus hepatopancreático}

Inicialmente limitado a algunos países de Asia, todos los reportes de presencia de este virus, se originaban en esta región o en la región del Indopacífico, por lo que posteriormente se le llegó a considerar como una especie exclusiva de Asia, África y Australia (Lightner y Pantoja, 2001).

Se han observado infecciones naturales en P. vannamei, $P$. stylirostris, $P$. merguiensis, $P$, semisulcatus, $P$. chinensis, $P$. esculentus, $P$. monodon, $P$. japonicus y $P$. penicillatus. Las mortalidades causadas por este virus, son difíciles de determinar, ya que generalmente se presenta en coinfecciones con otros patógenos, pero es capaz de causar debilidad y retardos en el crecimiento de los animales infectados (Lightner, 1996, Lightner y Pantoja, 2001).

Durante el año 1987 fue diagnosticado en camarones en Sur América importados desde Asia, así como en peneidos en Norteamérica, posterior a ello, ha sido detectado en la costa Pacífica mexicana y en Centro América (Lightner y Pantoja, 2001).

\section{Virus de la cabeza amarilla}

Este virus ha sido reportado en cultivos en Asia, causando grandes mortalidades. Virus relacionados filogenéticamente como el virus asociado a las branquias, se han detectado en Asia, África y Australia (OIE, 2016).

Las especies susceptibles para este agente son $P$. monodon, en poblaciones salvajes sanas de $P$. Stylirostris, además se han detectado infecciones naturales en $P$. japonicus, $P$. merguiensis, P. setiferus, Metapenaeus ensis y Euphasia superba (Lightner, 1996; Castro-Longoria et al. 2008; OIE, 2016). Adicional a lo anterior, se ha reportado que en infecciones experimentales de peneidos americanos juveniles, causa infecciones serias en las especies $P$. vannamei, $P$. stylirostris, $P$. setiferus, $P$. aztecus y $P$. duorarum (Lightner, 1996).

Este virus ha sido notificado en China, Indonesia, Malasia, Filipinas, Sri Lanka, Tailandia y Vietnam, así como otros genotipos del complejo de la cabeza amarilla en $P$. monodon sanos de Australia, Taipéi, La India, Indonesia, Malasia, Mozambique, Filipinas, Tailandia y Vietnam (Lightner, 1996; Bondad-Reantaso et al. 2001; Lightner y Pantoja, 2001; MoralesCovarrubias, 2010; OIE, 2016).

Posteriormente ha sido detectado en $P$. vannamei en México, sin provocar mortalidades. No se tiene claro el mecanismo de ingreso de este agente infeccioso al continente (de la Rosa et al, 2006; Castro-Longoria et al, 2008). En la actualidad no se dispone de reportes desde otras regiones de América.

\section{Necrosis aguda del hepatopáncreas}

Las infecciones bacteriales causados por diferentes especies no son un fenómeno reciente en la camaronicultura, múltiples publicaciones han asociado a este grupo con patologías importantes, siendo recurrente, pero no exclusiva, la participación de género Vibrio (Prieto y Rodríguez, 1993; Lightner, 1996; Martin et al. 2004: Aguirre-Guzmán et al. 2005; MoralesCovarrubias, 2010; Soto et al. 2010; Peña et al. 2013; Varela y Peña 2014; Morales-Covarrubias et al. 2015; Peña y Varela, 2016).

Sin embargo, durante los últimos años, una nueva patología bacterial ha cobrado gran relevancia por su impacto, virulencia y velocidad de propagación. Es causada por bacterias altamente patogénicas y que han sido identificadas inicialmente como Vibrio parahaemolyticus. Recientemente, se han publicado reportes de otras especies sospechosas de provocar el AHPND, se trata de una cepa de la especie Vibrio harveyi (Kondo et al, 2015) y de una cepa de Vibrio campbellii (Han et al, 2017).

Esta infección es capaz de dar lugar a un súbito aumento en la mortalidad de las poblaciones afectadas que se observa entre los primeros treinta a cuarenta días de cultivo, logrando eliminar hasta el $100 \%$ de los animales en los estanques infectados (Cuéllar-Ánjel et al. 2012; Tran et al. 2013; Joshi et al. 2014; Pantoja y Lightner, 2014b; Varela y Peña, 2016). Esta enfermedad ha sido llamada Necrosis aguda del hepatopáncreas (AHPND por sus siglas en inglés). 
Hasta el momento, solo se han confirmado infecciones por esta patología afectando a las especies $P$. vannamei y $P$, monodon en cultivo (NACA, 2012; Tran et al. 2013, Pantoja y Lightner, 2014; de la Peña et al. 2015).

Esta enfermedad fue reportada por primera vez en el año 2009 en camarones juveniles cultivados en China. En los años siguientes se propagó a países cercanos, afectando a Vietnam en el 2010, Malasia en el 2011 y Tailandia en el 2012 (NACA, 2012; FAO, 2013; Lightner, 2013; Tran et al. 2013; Varela y Peña, 2014) y más recientemente fue detectada en Filipinas durante el año 2015 (de la Peña et al. 2015).

El ingreso del AHPND al continente americano se documentó en el año 2013, generando altas mortalidades y disminución de producción en México, iniciando en la costa Pacífica (Nunan et al. 2014; Pantoja y Lightner, 2014a); por último, se reportó para Centro América en el 2015 (Han et al. 2015), donde se ha confirmado para Belice (Shrimp New Internacional, 2015), pero se sospecha de su presencia en toda la región.

\section{Discusión y conclusiones}

La transfronterización de enfermedades constituye un fenómeno que se ha visto influenciado y acelerado como consecuencia de la globalización que experimentamos en las actividades comerciales y productivas. El control de los agentes infecciosos que afectan a la acuicultura es de vital importancia y es necesario contar con herramientas que permitan prevenir y controlar posibles brotes. Existe una alerta generalizada sobre la importancia que tiene la prevención de las patologías en la camaronicultura, ya que la falta de control de los movimientos comerciales de los animales acuáticos a nivel mundial está causando propagaciones de enfermedades. Las cuales, una vez introducidas se establecidas en el nuevo ambiente natural, es prácticamente imposible de erradicar (de Blas y Muniesa, 2014).

Por ejemplo, Bondad-Reantaso indicó en el 2005 que "la región de Asia había aprendido a tratar con los brotes de enfermedades, utilizando las fuentes disponibles de animales, la experiencia y las instalaciones", obtenidas después de tres décadas de emergencias. A pesar de ello, en el 2006 la el virus de la mionecrosis infecciosa fue reportada en Asia por primera vez, presumiblemente de la costa Atlántica de Brasil. En el 2010, la región fue de nuevo afectada por otra patología, la necrosis aguda del hepatopáncreas. Estos brotes sugieren que las estrategias actuales de manejo de enfermedades no han sido completamente efectivas y se requieren cambios y mejoras, con el fin de reducir las probabilidades de futuras crisis (Cock et al, 2015).

Adicionalmente, tal como ha sido mencionado, algunas de estas patologías han afectado a las poblaciones naturales en forma constante, aunque aparentemente, su velocidad de propagación no suele ser tan elevada (de la Rosa et al, 2006).

Con el fin de evitar o minimizar estos efectos colaterales, los centros de producción camaronícola deben establecer y acatar planes de manejo preventivo de las enfermedades, los cuales deben incluir el monitoreo frecuente para evaluar el estado sanitario de las poblaciones, la reducción de factores de estrés, así como las fuentes potenciales de transmisión de enfermedades (Cuéllar-Ánjel et al, 2014).

Se han realizado múltiples esfuerzos con el fin de crear conciencia sobre la relevancia de maximizar los controles de sanidad y la implementación de sistemas y prácticas de bioseguridad (Arthur et al 2008; Cuéllar-Ánjel 2014).

Aunado a lo anterior, se dispone de numerosas técnicas y tecnología para el diagnóstico de enfermedades, entre las que se incluyen el análisis clínico, análisis en fresco, bacteriología, sistemas ELISA, inmunocromatografía de flujo lateral, histopatología y la reacción en cadena de la polimerasa, (Bell y Lightner, 1988; Prieto y Rodríguez, 1993; Lightner, 1996; MoralesCovarrubias, 2010; Cuéllar-Ánjel 2014). La existencia de conocimientos y técnicas, no parecen ser el problema.

La principal limitante parece ser la vulnerabilidad existente en las políticas de control y vigilancia, así como el déficit de personal eficazmente capacitado. En la mayoría de estos análisis, se requiere de médicos veterinarios especialistas o personal de áreas afines, 
adecuadamente entrenados. Adicionalmente, el diagnóstico no es un resultado de laboratorio como tal, sino la interpretación que hace el especialista en sanidad, con base en sus conocimientos y en la información recopilada de campo y de laboratorio de cada caso en particular (Cuéllar-Ánjel. 2014).

Una alternativa obvia que puede minimizar el riesgo de transfronterización de enfermedades, es el envío de muestras representativas previas a las importaciones, a laboratorios especializados ubicados localmente o en el exterior, ante dudas de presencia de alguna patología o como control previo al ingreso de materiales o animales peligrosos a zonas libres de brotes.

Como agravante, se presenta el riesgo de las patologías emergentes, actualmente se mantiene una alerta en América por los riesgos de ingreso de patógenos exóticos como el Enterocytozoon hepatopenaei, el cual es un microsporidio del hepatopáncreas, o el virus de la mortalidad encubierta, detectados en coinfecciones del AHPND en Asia (Huang, 2012; Zhang et al. 2014; Tang et al. 2015; Varela, 2016).

La globalización de productos acuícolas implicará el riesgo de ingreso de sus posibles patógenos, este desafortunado fenómeno posiblemente no será solventado en su totalidad, pero la aplicación de medidas de bioseguridad ha demostrado ser de gran ayuda en el pasado para reducir el impacto de las enfermedades que trascienden las fronteras.

Finalmente, la naturaleza de los patógenos que afectan a los camarones, así como al proceso al que se someten estos alimentos. Hacen que las patologías de crustáceos no representen un riesgo para los consumidores. Estos alimentos deben presentar menos riesgos para el consumidor que los alimentos terrestres, sus riesgos, de existir, están asociados a malas prácticas de manejo, las cuales pueden dar como resultado la contaminación por microorganismos (Varela, 2011). Por lo que la presencia de agentes infecciosos, no compromete la inocuidad de este producto para los consumidores. Pero obviamente, si pueden afectar la oferta de los mismos en el mercado, al disminuir sus producciones.

\section{Bibliografía consultada}

Aguirre-Guzmán, G.; Ascencio F.; Saulnier, D. 2005. Pathogenicity of Vibrio penaeicida for white shrimp Litopenaeus vannamei: a cysteine protease-like exotoxin as a virulence factor. Dis. Aquat. Org. 67: 201-207.

Arthur, J. R.; Baldock, C. F.; Bondad-Reantaso, M. G.; Perera, R.; Ponia, B.; Rodgers, C. J. 2008. Pathogen risk analysis for biosecurity and the management of live aquatic animal movements. In Bondad-Reantaso, M, G; Mohan, C, V; Crumlish, M; Subasinghe, R, P. (eds.). Diseases in Asian Aquaculture VI. Fish Health Section, Asian Fisheries Society, Manila, Philippines.

Balbuena, E. 2011. Manual básico de sanidad piscícola. FAO/ Ministerio de Agricultura y Ganadería (MAG). Uruguay.

Bell, T. A.; Lightner, D. V. 1988. A Handbook of Normal Penaeid Shrimp Histology. World Aquaculture Society, Baton Rouge, LA, USA.

Bondad-Reantaso, M. G.; Arthur, J. R. 2008. Pathogen risk analysis for aquaculture production. In M.G. BondadReantaso, J.R. Arthur and R.P. Subasinghe (eds). Understanding and applying risk analysis in aquaculture. FAO Fisheries and Aquaculture Technical Paper. No. 519. Rome, FAO.

Bondad-Reantaso, M. G.; Mc Gladdery, S. E.; East, I.; Subasinghe, R. P. 2001. Asia Diagnostic Guide to Aquatic Animal Diseases. FAO Fisheries Technical Paper No. 402, Supplement 2. Rome, FAO. 2001. 240 p.

Castro-Longoria, R.; Quintero-Arredondo, N.; GrijalvaChon, J. M.; Ramos-Paredes, J. 2008. Detection of the Yellow-head virus (YHV) in wild blue shrimp, Penaeus stylirostris, from the gulf of California and its experimental transmission to the pacific white shrimp, Penaeus vannamei. J. Fish dis., 31 (12), 953-956.

Cock, J.; Salazar, M.; Rye, M. 2015. Strategies for managing diseases in non-native shrimp populations. Reviews in Aquaculture (2015) 0, 1-16.

Chan, B. K. K.; Nam Poon, B.; Walker, G. 2005. Distribution, adult morphology, and larval development of Sacculina sinensis (Cirripedia: Rhizocephala: Kentrogonida) in Hong Kong coastal waters. Journal of crustacean biology, 25(1): 1-10, 2005.

Cuéllar-Ángel, J. 2014. Métodos para el Diagnóstico de Enfermedades en Camarones Penaeidos. En: Morales, 
V. y J. Cuéllar-Ánjel (eds.). 2014. Guía Técnica Patología e Inmunología de Camarones Penaeidos. OIRSA, Panamá.

Cuéllar-Ángel, J.; Lightner, D. V.; Pantoja, C. 2012. Síndrome de Mortalidad Temprana o Síndrome de Necrosis Hepatopancreática Aguda. Panorama Acuícola Magazine. Nov-Dic. 42-43.

Cuéllar-Ánjel, J.; Morales, V.; Lara, C.; García, O. 2014. Buenas prácticas y bioseguridad para el cultivo del camarón blanco Penaeus (Litopenaeus) vannamei (Boone, 1931) En: Morales, V. y J. Cuéllar-Ánjel (eds.). 2014. Guía Técnica - Patología e Inmunología de Camarones Penaeidos. OIRSA, Panamá.

de Blas, I.; Muniesa, A. 2014. Vigilancia Epidemiológica en Camaronicultura. En: Morales, V. y J. Cuéllar-Ánjel (eds.). 2014. Guía Técnica - Patología e Inmunología de Camarones Penaeidos. OIRSA, Panamá.

de la Peña, L.; Cabillon, N.; Catedral, D.; Amar, E.; Usero, R.; Monotilla, W.; Calpe, A.; Fernández, D.; Saloma, C. 2015. Acute hepatopancreatic necrosis disease (AHPND) outbreaks in Penaeus vannamei and P. monodon cultured in the Phillipines. Disease of aquatic organisms. 116: 251-254.

de Rosa J.; Cedano, Y.; Cid, J.; Méndez, J. C.; Vega, C.; Zambrano, J.; Bonami, J. 2006. Presumptive detection of yellow head virus by reverse transcriptase-polymerase chain reaction and dot-blot hybridization in Litopenaeus vannamei and L. stylirostris cultured on the Northwest coast of Mexico. J. Fish. Dis. 29 (12), 717-726.

Diéguez-Uribeondo, J. 1998. El Cangrejo de Río: Distribución, Patología, Inmunología y Ecología. Revista AquaTIC no 3 (Mayo 1998).

Diggles, B. K. 1999. Diseases of spiny lobsters in New Zealand. Proceedings, International Symposium on Lobster Health Management, Adelaide.

FAO. 2013. Report of the FAO/MARD Technical Workshop on Early Mortality Syndrome (EMS) or Acute Hepatopancreatic Necrosis Syndrome (AHPNS) of Cultured Shrimp (under TCP/VIE/3304).

FAO. 2016. El estado mundial de pesca y la acuicultura. Departamento de Pesca y Acuicultura. Contribución a la seguridad alimentaria y la nutrición para todos. Roma. Italia. 224 pp.
Han, J.; Tang, K.; Aranguren, L, F.; Piamsomboon, P. 2017. Characterization and pathogenicity of acute hepatopancreatic necrosis disease natural mutants, pir $\mathrm{AB}_{\mathrm{vp}}$ (-) V. parahaemolyticus, and pir $\mathrm{AB}_{\mathrm{vp}}(+) \mathrm{V}$. campbellii strains. Aquaculture 470 (2017) 84-90.

Han, J.; Tang, K.; Lightner, D. V. 2015. Genotyping of virulence plasmid from Vibrio parahaemolyticus isolates causing acute hepatopancreatic necrosis disease in shrimp. Dis Aquat Org. Vol. 115: 245-251, 2015.

Hendrickx, M. E. 1995. Camarones. Guía FAO para la identificación de especies para los fines de pesca. Pacífico Oriental. Vol. 1. Plantas e invertebrados. Roma, Italia.

Huang, J. 2012. Experiences in EMS/AHPNS from China. On Network of Aquaculture Centers in Asia-Pacific Regional Consultation on the Emerging Shrimp Disease: Early Mortality Syndrome (EMS) / Acute Hepatopancreatic Necrosis Syndrome (AHPNS). Final Report.

Joshi, J.; Srisala, J.; Truong, V. H.; Chen, I. T.; Nuangsaeng, B.; Suthienkul, O.; Lo, C. F.; Flegel, T. W.; Sritunyalucksana, K.; Thitamadee, S. 2014. Variation in Vibrio parahaemolyticus isolates from a single Thai shrimp farm experiencing an outbreak of acute hepatopancreatic necrosis disease (AHPND). Aquaculture (428-429): 297-302.

Kinne, O. 1990. Diseases of Marine animals, Volume III. Ecology Institute Nordbiinte, Germany. Biologische Anstalt Helgoland. Hamburg, Germany.

Kondo, H.; Van, P. T.; Dang, L. T.; Hirono, I. (2015). Draft genome sequence of non-Vibrio parahaemolyticus acute hepatopancreatic necrosis disease strain KC13.17.5, isolated from diseased shrimp in Vietnam. Genome Announc. 3(5): 1-3.

Lee, D.; Wickins, J. 1992. Crustacean farming. Oxford. Blackwell Scientific Publications. London. England.

Lightner, D. V. 1996. A handbook of shrimp pathology and diagnostic procedures for diseases of cultured penaeid shrimp. World Aquaculture Society, Baton Rouge, Lousiana, USA.

Lightner, D. V.; Pantoja, C. 2001. Manual para el Diagnóstico de Enfermedades del Camarón. United States Department of Agriculture - Programa de Reconstrucción Huracán Mitch. USDA/CSREES/ USAID/UAZ). 
López, J.; Ojeda, J. Creainnova. 2012. Guía de buenas prácticas para reducir el impacto de las actividades acuícolas sobre el medio ambiente y llevar a cabo una gestión Sostenible de las especies cultivadas. Proyecto Acuiverde. Gobierno de España. Ministerio de Alimentación y Medio Ambiente. Fundación Biodiversidad. Emplea verde 2007-2013. Unión Europea. Editorial APROMAR.

Martin, G.; Rubin, N.; Swanson, E. 2004. Vibrio parahaemolyticus and $V$. harveyi cause detachment of the epithelium from the midgut trunk of the penaeid shrimp Sicyonia ingentis. J. Dis. Aqua. Org. 60: 21-29.

Martorelli, S. R.; Tapella, F.; Marcotegui, P.; Romero, C. 2003. Estudio preliminar de los parásitos y epibiontes de la Langostilla Munida subrugosa (Decapoda, Anomura, Galatheidae) del Canal Beagle, Tierra del Fuego (Argentina). CIVA 2003 (http://www.civa2003. org), 399-419.

Morales-Covarrubias, M. S. 2010. Enfermedades del camarón: detección mediante análisis en fresco e histopatología. Editorial Trillas. México.

Morales-Covarrubias, M. S.; Cuéllar-Ánjel, J.; VarelaMejías, A.; Elizondo-Ovares, C. 2015. Principales enfermedades bacterianas de camarones en Latinoamérica. FAO-OIRSA. Seminario / Taller 1, EMS/AHPND: Reducción y Gestión del Riesgo de la enfermedad de la necrosis aguda del Hepatopáncreas (AHPND) en cultivos de camarones.

Morales, V.; Cuéllar-Ánjel, J. (eds.). 2014. Guía Técnica - Patología e Inmunología de Camarones Penaeidos. OIRSA, Panamá.

NACA. 2012. Network of Aquaculture Centers in AsiaPacific Regional Consultation on the Emerging Shrimp Disease: Early Mortality Syndrome (EMS) / Acute Hepatopancreatic Necrosis Syndrome (AHPNS).

Noga, E. J.; Smolowitz, R.; Khoo, L. H. 2000. Pathology of shell disease in the blue crab, Callinectes sapidus Rathbun, (Decapoda: Portunidae). Journal of Fish Diseases 2000, 23, 389-399.

Nunan, L.; Lightner, D. V.; Pantoja, C.; Gómez-Jiménez, S. 2014. Detection of acute hepatopancreatic necrosis disease (AHPND) in Mexico. Dis Aquat Org. Vol. 111: 81-86, 2014.

OIE. 2016. Organización Mundial de Sanidad Animal. Manual de diagnóstico en animales acuáticos. 6 ed. Paris, Francia.
Pantoja, C.; Lightner, D. V. 2014a. Enfermedades virales. En: Morales, V. y J. Cuéllar-Ánjel (eds.). 2014. Guía Técnica - Patología e Inmunología de Camarones Penaeidos. OIRSA, Panamá.

Pantoja, C.; Lightner D. V. 2014b. EMS/AHPND descripción de la enfermedad en Asia y América. P. 172-177. En: Morales, V. y Cuéllar-Ánjel (eds). 2014. Guía Técnica - Patología e Inmunología de Camarones penaeidos. OIRSA, Panamá, Rep. de Panamá. 382p.

Peña, N.; Varela, A. 2016. Prevalencia de las principales enfermedades infecciosas en el camarón blanco Penaeus vannamei cultivado en el Golfo de Nicoya, Costa Rica. Revista de Biología Marina y Oceanografía. Chile. Vol. 51, No3: 553-564.

Peña, N.; Vargas, R.; Varela, A. 2013. Productos naturales como estimuladores del sistema inmunológico de Litopenaeus vannamei, infectado con Vibrio parahaemolyticus. Agronomía Mesoamericana 24(1):133-147.

Pereira, A.; M. L.; Shinozaki, E.; Vasconcelos, C.; Da Silva, V.; Benedita, A. 2014. Mionecrosis infecciosa viral - IMNV y sus implicaciones en el cultivo de camarón brasileño. En: Morales, V. y J. Cuéllar-Ánjel (eds.). 2014. Guía Técnica - Patología e Inmunología de Camarones Penaeidos. OIRSA, Panamá.

Pestal, G. P.; Taylor, D., M.; Hoenig, J. M.; Shields, J. D.; Pickavance, R. 2003. Monitoring the prevalence of the parasitic dinoflagellate Hematodinium sp. in snow crabs Chionoecetes opilio from Conception Bay, Newfoundland. Dis Aquat Org 53: 67-75, 2003.

Prieto, A.; Rodríguez, M. C. 1993. Diagnóstico y control de enfermedades bacterianas en camarón de cultivo. México: FAO.

Rai, P.; Safeena, M.; Krabsetsve, K.; La Fauce, K.; Owens, L.; Karunasagar, I. 2012. Genomics, Molecular Epidemiology and Diagnostics of Infectious hypodermal and hematopoietic necrosis virus, Review article. Indian J. Virol. (July-September 2012) 23(2): 203-214.

Senapin, S.; Phewsaiya, K.; Griggs, M.; Flegel, T. W. 2007. Outbreaks of infectious myonecrosis virus (IMNV) in Indonesia confirmed by genome sequencing and use of an alternative RT-PCR detection method. Aquaculture, Vol. 266. 32-389 pp.

Shields, J. D. 2001. Ovicides julieae n. Gen., n. Sp. (Nemertea: Carcinonemertidae) on Xanthid crabs 
from the Great Barrier Reef, Australia. Journal of crustacean biology, 21(1): 304-312, 2001.

Shrimp News International. 2015. Belize Recovers from EMS. Tomado de https://www.shrimpnews. com/FreeReportsFolder/NewsReportsFolder/ MexicoAndBelizeElNinoAndEMS.html

Stentiford, G. D.; Green, M.; Bateman, K.; Small, H. J.; Neil, D. M.; Feista, S. W. 2002. Infection by a Hematodinium-like parasitic dinoflagellate causes Pink Crab Disease (PCD) in the edible crab Cancer pagurus. Journal of Invertebrate Pathology 79 (2002) 179-191.

Soto, S.A.; Gómez-Gil, B.; Lozano, R. 2010. 'Bright-red' syndrome in Pacific white shrimp Litopenaeus vannamei is caused by Vibrio harveyi. J. Dis. Aquat. Org. 92:11-19.

Soto, M. A.; Shervette, V. R.; Lotz J. M. 2001. Transmission of white spot syndrome virus (WSSV) to Litopenaeus vannamei from infected cephalothorax, abdomen, or whole shrimp cadaver. Dis. Aquat. Org. 45: 81-87.

Tang, K.; Navarro, S.; Pantoja, C.; Aranguren, F.; Lightner, D. V. 2012. New genotypes of white spot syndrome virus (WSSV) and Taura syndrome virus (TSV) from the Kingdom of Saudi Arabia. Dis. Aquat. Org., 99, 179-185.

Tang, H.; Pantoja, C.; Redman, R.; Han, J., E.; Tran, L.; Lightner, D. V. 2015. Development of in situ hybridization and PCR assays for the detection of Enterocytozoon hepatopenaei (EHP), a microsporidian parasite infecting penaeid shrimp. J. of Invertebrate Pathology. Vol 130: 37-41.

Tran, L.; Nunan, L.; Redman, R.; Mohney, L.; Pantoja, C.; Fitzsimmons, K.; Lightner, D. V. 2013. Determination of the infectious nature of the agent of acute hepatopancreatic necrosis syndrome affecting penaeid shrimp. Dis. Aquat. Organ. 105, 45-55.

Tu, C.; Huang, H. T.; Chuang, S. H.; Hsu, J. P.; Kuo, S. T.; Li, N. J.; Hus, T. L.; Li, M. C.; Lin, S. Y. 1999. Taura syndrome in Pacific white shrimp Penaeus vannamei cultured in Taiwan. Dis. Aquat. Org., 38, 159-161.

Varela, A. 2011. Equipamiento y establecimiento de protocolos en un laboratorio de control de calidad bacteriológica para una planta procesadora de mariscos. Proyecto profesional. Universidad Estatal a Distancia.
Varela, A. 2016. Nodavirus de la mortalidad encubierta (CMNV) en camarones marinos de cultivo. Nota técnica. Rev. Repertorio Científico, Universidad Estatal a Distancia. Vol. 19, $\mathrm{N}^{\circ} 1$ : 2016: 33-40.

Varela, A; Peña, N. 2013. El Virus del Síndrome de las Manchas Blancas (WSSV): una revisión y su impacto en la camaronicultura costarricense. Rev. Ciencias Veterinarias, 28 (2): 51-69.

Varela, A; Peña, N. 2014. Síndrome de la Mortalidad Temprana (EMS/AHPNS) en camarones cultivados: Una revisión. Revista Repertorio Científico. Universidad Estatal a Distancia C.R. Vol. 17, $\mathrm{N}^{\circ} 1$. 2014: 25-30.

Varela, A.; Peña, N. 2016. Histopatología diferencial de tres enfermedades bacterianas que afectan el hepatopáncreas de camarones peneidos. Rev. Agron. Mesoam. 27(1): 73-80. 2016 ISSN 1021-7444.

Vega-Heredia, S.; Mendoza-Cano, F.; SánchezPaz, A. 2011. The Infectious hypodermal and Hematopoietic Necrosis Virus: A Brief Review of What We Do and Do Not Know. Transboundary and Emerging Diseases. Blackwell Verlag $\mathrm{GmbH}$. doi:10.1111/j.1865-1682.2011.01249.x

Vieira, R. H. S. F.; Lima, E. A.; Sousa, D. B.; Reis, E. F.; Costa, R. G.; Rodrigues, D. P. 2004. Vibrio spp. and Salmonella spp., presence and susceptibility in crabs Ucides cordatus. Rev. Inst. Med. trop. S. Paulo, 46(4): 179-182, 2004.

Vogt, G. 2012. Ageing and longevity in the Decapoda (Crustacea): A review. Zoologischer Anzeiger 251 (2012) 1-25.

Walker, P. J.; Winton, J. R. 2010. Emerging viral diseases of fish and shrimp. Veterinary Research, 41(6), 51.

Wheeler, K.; Shields, J. D.; Taylor, D. M. 2007. Pathology of Hematodinium infections in snow crabs (Chionoecetes opilio) from Newfoundland, Canada. Journal of Invertebrate Pathology 95 (2007) 93-100.

Zhang, Q.; Liu, S.; Yang, H.; Liu, S.; Zhu, L.; Yang, B.; Jin, J.; Ding, L.; Wang, X.; Liang, Y.; Wang Q.; Huang, J. 2014. A new nodavirus is associated with covert mortality disease of shrimp. Journal of General Virology, 2014: 95, 2700-2709. 
